\title{
Dispersion of Iron Nanoparticles by Polymer-Based Hybrid Material for Reduction of Hexavalent Chromium
}

\author{
Syed Wasim Ali, ${ }^{1,2}$ Mumammad Latif Mirza, ${ }^{1,3}$ Tariq M. Bhatti, \\ Kashif Naeem, ${ }^{5}$ and Muhammad Imran Din ${ }^{6}$ \\ ${ }^{1}$ Department of Chemistry, Islamia University of Bahawalpur, Bahawalpur, Pakistan \\ ${ }^{2}$ Chemistry Division, Pakistan Institute of Nuclear Science and Technology (PINSTECH), P.O. Nilore, Islamabad 45650, Pakistan \\ ${ }^{3}$ Department of Chemistry, University of Sargodha, Pakistan \\ ${ }^{4}$ Department of Chemical Engineering, Pakistan Institute of Engineering and Applied Sciences (PIEAS), P.O. Nilore, \\ Islamabad 45650, Pakistan \\ ${ }^{5}$ Central Analytical Facility Division, Pakistan Institute of Nuclear Science and Technology (PINSTECH), P.O. Nilore, \\ Islamabad 45650, Pakistan \\ ${ }^{6}$ Institute of Chemistry, University of the Punjab, Lahore, Pakistan
}

Correspondence should be addressed to Muhammad Imran Din; imrandin2007@gmail.com

Received 23 June 2015; Accepted 30 August 2015

Academic Editor: John Zhanhu Guo

Copyright (C) 2015 Syed Wasim Ali et al. This is an open access article distributed under the Creative Commons Attribution License, which permits unrestricted use, distribution, and reproduction in any medium, provided the original work is properly cited.

\begin{abstract}
A gel type acrylic acid resin, based on ethyl acrylate-co-1,7-octadiene, has been synthesized by suspension polymerization at $20 \%$ cross-linking and subsequent hydrolysis by $\mathrm{H}_{2} \mathrm{SO}_{4}$. Capacity of the resin was observed to be $8.90 \mathrm{meq} / \mathrm{g}$ or $3.28 \mathrm{meq} / \mathrm{mL}$. The iron nanoparticles used in this study were synthesized by ferrous sulphate method by using $\mathrm{LiBH}_{4}$ as a reductant and characterized by SEM, TEM, XRD, surface area, and electrical properties. Later, the resin was applied for the dispersion of iron nanoparticles over its surface for the reduction of $\mathrm{Cr}(\mathrm{VI})$ and subsequent adsorption of $\mathrm{Fe}(\mathrm{III})$ and $\mathrm{Cr}(\mathrm{III})$ as byproducts. In the column studies the reduction of $\mathrm{Cr}(\mathrm{VI})$ and the adsorption of $\mathrm{Cr}(\mathrm{III})$ and $\mathrm{Fe}(\mathrm{III})$ have been observed up to $240 \mu \mathrm{mole} / \mathrm{L}$.
\end{abstract}

\section{Introduction}

Cation-exchange resins have wide spread applications in water softening, removal of toxic metals from water in the environment, wastewater treatment, hydrometallurgy, sensors, chromatography, and biomolecular separations [1]. In the environment applications, the use of cation-exchange resins has advantage over the other techniques due to better selectivity of the resins for metals, production of less sludge volume, compliance with strict discharge specifications, and easy regeneration for the next applications [2]. A large number of classes of cation-exchange resins have been synthesized so far of different strengths and selectivity, but the use of appropriate resin for particular applications depends upon the attached functional groups. Among the different cationexchange resins, the carboxylic acid resins are of considerably weaker acid strength ( $p K_{a}$ values in the range of 4-6) than their sulphonic acid counterpart [3]. Some of the features of weak acid resins are the following: these can work in neutral and basic solutions [4], have higher selectivity towards heavy metal ions, are easier to regenerate compared to $-\mathrm{SO}_{3} \mathrm{H}$ groups [5], have high capacity; twice that of strong-cation resins and 3-4 times that of chelating resins, low cost and have faster kinetics compared to chelating resins [6]. Despite these good features, still weak acid cation exchange resins are considered to be unfamiliar in scientist community and thus less literature is available, in either its synthesis or its applications.

In the present study 1,7-octadiene was used as a crosslinker in the synthesis of acrylic acid resin, which gives the whole structure more flexible as reported in our previous study where n-heptane was used as a diluent and later the resin was applied for picking metal ions from aqueous media [7]. In the present study, the synthesized resin was applied as a polymer support material for the removal of chromium(VI) from water which is based on oxidation reduction process by 
using iron nanoparticles in two processes. In the first process the iron nanoparticles were dispersed over the surface of the resin, which act as a polymer support. When chromium(VI) comes under the potential of $\mathrm{Fe}^{0}$, the net result is the reduction of chromium(VI) to chromium(III) onto the surface of the support material which is a cation exchanger [8]. The dispersion of iron nanoparticles onto the surface of support material is necessary because the iron nanoparticles have high tendency to undergo oxidation, hydrolysis, and agglomeration into microparticles that have become low reactive [9]. Most commonly used support material for the dispersion of iron nanoparticles is Poly-Flo resin [9] which is neutral in character but the resin with ionic moiety has extra advantages as this enriches the cationic byproduct from the same aqueous media $[8,10-12]$. Use of polymer support to disperse iron oxide nanoparticles like iron nanoparticles has also been reported by many authors [12-14]. So in our present study, the use of weak acid cationic support material is also helpful for the capturing of produced ions, that is, $\mathrm{Cr}$ (III) and $\mathrm{Fe}$ (III) from the reaction mixture in a single step. $\mathrm{Cr}(\mathrm{VI})$ is considered to be a potential toxic and carcinogenic material and the maximum permissible dose level of $\mathrm{Cr}(\mathrm{VI})$ is $0.05 \mathrm{mg} / \mathrm{L}$; on the other hand $\mathrm{Cr}(\mathrm{III})$ species are not toxic and necessary to mammalian system except at elevated dose and their allowed dose in the drinking water is $5 \mathrm{mg} / \mathrm{L}$ [15]. Thus second process is the capturing of newly produced $\mathrm{Cr}$ (III) and $\mathrm{Fe}$ (III) ions by weak acid resin which is equally important. For the removal of $\mathrm{Cr}$ (III) from water, Zeolite 3A [16], Zeolite 5A [17], sphagnum moss peat [18], carbon [19], and so forth, and for the Fe(III) ions from water, bamboo charcoals [20], vermiculite [21], and so forth, are some of the examples that have been reported in the past few years, but the methods based on ion exchange for the capturing of the metal ions from aqueous media have some extra advantages including its repeated use after regeneration [1]. Thus the present utility of the weak acid resin as a polymer support and the degradation of $\mathrm{Cr}(\mathrm{VI})$ and finally removal of degraded products from water is a new era in the field of weak acid cation exchanger.

\section{Experimental}

2.1. Chemicals. The reagents used for polymerization, ethyl acrylate from Merck, 1,7-octadiene, benzyl peroxide ( $97 \%$ purity moisture with $25 \%$ water) from Fluka. Other reagents like $\mathrm{LiBH}_{4}$ was obtained from Merck. FeSO $\cdot 7 \mathrm{H}_{2} \mathrm{O}$ and $\mathrm{K}_{2} \mathrm{Cr}_{2} \mathrm{O}_{7}$ was obtained from Fluka. Demineralized water was distilled and the product water having conductivity $\sim 1.5 \mu \mathrm{S} / \mathrm{cm}$ were used in all the experiments. All other reagents for characterization were of analytical grade.

2.2. Synthesis of Copolymer. The copolymer in the form of beads was prepared by suspension polymerization as reported recently [7]. Briefly the polymerization mixture consisting of ethyl acrylate and 1,7-octadiene was 4:1 ratio. Benzoyl peroxide was added in each polymerization mixture $1 \%$ by weight. Aqueous phase was prepared by dissolving gum-Arabic and gelatin by $1 \% \mathrm{w} / \mathrm{v}$ each in distilled water. One part by volume of the polymerization mixture was suspended in five parts of the aqueous phase under mechanical stirring. The suspension was left under stirring for half an hour at room temperature. The temperature was then raised to $80^{\circ} \mathrm{C}$ in $\sim 20 \mathrm{~min}$ and maintained at $80^{\circ} \mathrm{C}$ for 20 hours while mechanical stirring was continued. The copolymer beads were then filtered out in a Buckner funnel and washed with hot water to get free from gelatin and gum-Arabic and then washed with acetone to get free from diluents and unreacted homopolymers. The excessive acetone was removed by centrifugation and the volume of the swelled beads $\left(V_{s}\right)$ was recorded. The beads were dried at $110^{\circ} \mathrm{C}$ until constant weight and the product was kept for acid hydrolysis.

\subsection{Hydrolysis of Ethyl-Acrylate-1,7-Octadiene Copolymer.} Acid hydrolysis of dried copolymer was carried out in $100 \mathrm{~mL}$ round bottom flask fitted with reflux and thermometer. $5 \mathrm{~g}$ of oven dried copolymer beads was mixed with $40 \mathrm{~mL}$ of $98 \% \mathrm{H}_{2} \mathrm{SO}_{4}$ at $96^{\circ} \mathrm{C}$ for 2 hours under constant stirring. After completion of reaction, flask was poured into $1 \mathrm{~L}$ of cold demineralized water and the beads were filtered out and washed with demineralized distilled water till the effluent was free of acid. The beads then segregated in the desired fraction with sieve. The colorless beads changed to black.

2.4. Density. The density $(d)$ of the dried hydrolyzed beads was calculated by $d=W_{d} / V_{d}$, where $W_{d}$ is the weight of the dried beads and $V_{d}$ is the volume of died beads at $110^{\circ} \mathrm{C}$ for 24 hours.

2.5. Capacity. The known amount of resin loaded in a column of $1 \mathrm{~cm}$ diameter and passed $100 \mathrm{~mL}$ of $2 \mathrm{M} \mathrm{HCl}$ which was neutralized by passing approximately $200 \mathrm{~mL}$ demineralized distilled water. Then $200 \mathrm{~mL}$ of $0.2 \mathrm{M} \mathrm{NaOH}$ was passed through the column followed by $50 \mathrm{~mL}$ demineralized distilled water. The $250 \mathrm{~mL}$ of the effluent was titrated to analyze the $\mathrm{NaOH}$ concentration. Milli moles of $\mathrm{NaOH}$ consumed in the resin are equal to the milli moles of -COOH groups in the resin [7] as given in the following equation:

$$
\mathrm{P}-\mathrm{COOH}+\mathrm{NaOH} \longrightarrow \mathrm{P}-\mathrm{COONa}+\mathrm{H}_{2} \mathrm{O}
$$

where $\mathrm{P}$ is the polymer chain. The resins containing carboxylic acid groups are effective in neutral and alkaline solution, and furthermore the reverse reaction is very effective by hydrogen ion; thus the regeneration can be accomplished readily at efficiencies approaching $100 \%$ [4].

2.6. FTIR Analysis. The FTIR spectra of this synthesized resin were recorded after minimizing the moisture present in the sample by NICOLET 6700 FTIR spectrophotometer.

2.7. Particle Analysis. The average particle size, surface area, and dispersal coefficient of the dried hydrolyzed resin was determined by BT 2002 laser particle size analyzer.

2.8. Synthesis of Iron Nanoparticles. The method of synthesis of iron nanoparticles was similar as reported earlier [22]. Briefly, first $6.15 \mathrm{~g}$ of $\mathrm{FeSO}_{4} \cdot 7 \mathrm{H}_{2} \mathrm{O}$ was dissolved in $50 \mathrm{~mL}$ 
demineralized water having conductivity nearly $1.5 \mu \mathrm{S} / \mathrm{cm}$. $\mathrm{pH}$ of this solution was adjusted to 7.00 by adding $3.8 \mathrm{M}$ $\mathrm{NaOH}$ solution. The color of the solution changed to orange. The $\mathrm{FeSO}_{4} \cdot 7 \mathrm{H}_{2} \mathrm{O}$ solution was transferred to $1000 \mathrm{~mL}$ vacuum flask and nitrogen gas was supplied to create inert atmosphere in the reaction flask. The contents were kept under fast and constant stirring at ambient temperature. Then $1.72 \mathrm{~g}$ of $\mathrm{LiBH}_{4}$ was added slowly to the mixture. Reaction proceeded very fast with large foaming and effervescence. The color of the reaction mixture finally changed to black. Stirring was continued for another 30-40 minutes. The black precipitates were filtered and washed with demineralized water followed by washing with excess acetone. The filtrate after washing was collected and analyzed by atomic absorption spectroscopy to estimate the percentage conversion of $\mathrm{FeSO}_{4} \cdot 7 \mathrm{H}_{2} \mathrm{O}$ to nano$\mathrm{Fe}^{0}$. Final product (iron nanoparticles) was stored in acetone for further studies.

2.9. Dispersion of Iron Nanoparticles on Polymer Support. In the ethanol-acetone mixture $(1: 4)$, the nano-Zero Valent Iron $(\mathrm{n}-\mathrm{ZVI})$ was dispersed in a $1: 10 \mathrm{w} / \mathrm{w}$ ratio. Then this dispersed mixture was combined with the known weight of weak acid resin. The slurry of the mixture was sonicated for about 10 minutes and continuously shaken for another 2 hours [23]. Later the composite of iron nanoparticles and weak acid polymer was centrifuged to remove excessive acetone and then dried in vacuum oven at $50^{\circ} \mathrm{C}$ and stored in desiccators for further studies.

2.10. Estimation of Iron in the Composite. Freshly prepared polymer-based hybrid materiel in a dried form was immersed in $30 \mathrm{~mL}$ of $0.1 \mathrm{M} \mathrm{HCl}$ solution and left under constant agitation for 8 hours. Then composite/hybrid material was further washed with distilled water three times. The effluents were combined and analyzed for iron contents by atomic adsorption spectroscopy using Hitachi Z 8000 atomic absorption spectrometer [22].

2.11. Characterization of Iron Nanoparticles (INPs). Analytical scanning electron microscope was used to determine the morphology of INPs. The samples were coated with gold with JFC-1500 ion sputtering device prior to taking images. Size assessment of the synthesized INPs was carried out by using JEOL transmission electron microscope (JEM-1010) with acceleration voltage range of $40-100 \mathrm{KV}$. The samples were dispersed with methanol in a sonicator. For the electrical characterization, the current voltage measurements were taken at room temperature using the agilent E4980 LCR meter. Prior to analysis the sample of iron nanoparticles was converted to pellets of $10 \mathrm{~mm}$ size at the pressure of 3 tons by STENHØJ 25 hydraulic press. BET surface area of the synthesized iron nanoparticles was measured (5point isotherm) by using nitrogen adsorption method with a Micromeritics Instrument Co., Surface Area Analyzer. The sample was dried/degassed automatically overnight under the flow of nitrogen, prior to the analysis. XRD analysis was performed using a Rigaku Diffractometer with a high power
$\mathrm{Cu} \mathrm{K} \alpha$ radioactive source $(\lambda=1.5406 \AA)$. The sample was scanned from $5^{\circ}$ to $90^{\circ} 2 \theta$ at a scanning rate of $0.32 \theta / \mathrm{min}$.

\subsection{Reduction of Cr(VI) and Enrichment of Cr(III) and Fe(III)}

2.12.1. Column Method. Polymer supported iron nanoparticles in a dried form loaded in a glass column of $1 \mathrm{~cm}$ diameter. Then $\mathrm{K}_{2} \mathrm{Cr}_{2} \mathrm{O}_{7}$ solution of different concentrations and known volumes were passed through it with a flow rate of $2 \mathrm{~mL} / \mathrm{min}$. The residues obtained were analyzed by diphenyl carbazide method for $\mathrm{Cr}(\mathrm{VI})$ concentration and for total $\mathrm{Cr}$ and Fe by atomic adsorption method. The reduction and simultaneous enrichment into weak acid polymer supported were calculated by the following relationship [22]:

$$
q_{e}(\mu \mathrm{mol} / \mathrm{g})=\left(C_{o}-C_{e}\right) \times \frac{V}{m},
$$

where $q_{e}$ adsorption capacity in $(\mu \mathrm{mol} / \mathrm{g}), C_{o}, C_{e}$ are the initial and residual concentrations, respectively, in $\mu \mathrm{mol} / \mathrm{L}$, $V$ is total volume of solution in liter, and $m$ is the weight of $\mathrm{Fe}^{0}$ in the supported resin in grams. In a similar way the adsorption of $\mathrm{Cr}(\mathrm{III})$ and $\mathrm{Fe}(\mathrm{III})$ ion produced as a result of reduction of $\mathrm{Cr}(\mathrm{VI})$ and subsequently captured by cationic support can be calculated on the basis of the total weight of the weak acid polymer support. The distribution coefficient $(D)$ can be calculated by the following equation:

$$
D(\mathrm{~L} / \mathrm{g})=\frac{q_{e}}{C_{e}} .
$$

2.12.2. Batch Method. Batch equilibrium adsorption isotherm studies were performed with aqueous solution of $\mathrm{Cr}(\mathrm{VI})$ at $96.1 \mu \mathrm{mol} / \mathrm{L}$ at $\mathrm{pH}$ 5.2. The iron nanoparticles dosage varies 40 to $78 \mathrm{mg} / \mathrm{g}$ of the resin in all the experiments. $1 \mathrm{~g}$ supported composite material and $25 \mathrm{~mL}$ solution were mixed in an Erlenmeyer flask for 150 minutes of shaking at $120 \mathrm{rpm}$ to reach equilibrium. The solutions were periodically pipette out for the analysis. Parameters like effect of amount of $\mathrm{n}-\mathrm{ZVI}$ towards the fixed concentration of $\mathrm{Cr}(\mathrm{VI})$ and effect of amount of $\mathrm{Cr}(\mathrm{VI})$ towards the fixed amount of reacting $\mathrm{n}$ ZVI have been calculated by using (2).

The equilibrium data has been applied to Freundlich isotherm model to describe the interaction of $\mathrm{Cr}(\mathrm{VI})$ with $\mathrm{n}$ ZVI and the adsorption of the newly generated ions towards the polymer support material. The linear form of Freundlich adsorption isotherm is [24]

$$
\ln q_{e}=\ln K_{F}+\left(\frac{1}{n}\right) \ln C_{e} .
$$

The kinetics parameters were studied with respect to the degradation of $\mathrm{Cr}(\mathrm{VI})$ to $\mathrm{Cr}(\mathrm{III})$ and the absorption of $\mathrm{Cr}$ (III) and $\mathrm{Fe}(\mathrm{III})$ by ion exchange support material at constant temperature. The degradation rate of $\mathrm{Cr}(\mathrm{VI})$ to $\mathrm{Cr}(\mathrm{III})$ by the reaction of $\mathrm{n}-\mathrm{ZVI}$ and ion exchange kinetics of $\mathrm{Cr}(\mathrm{III})$ and $\mathrm{Fe}$ (III) towards cation resin support material were tested by using pseudo-first-order and pseudo-secondorder sorption equations. The pseudo-first-order equation is given as follows:

$$
\ln \left(q_{e}-q_{t}\right)=\ln q_{e}-k_{1} t
$$




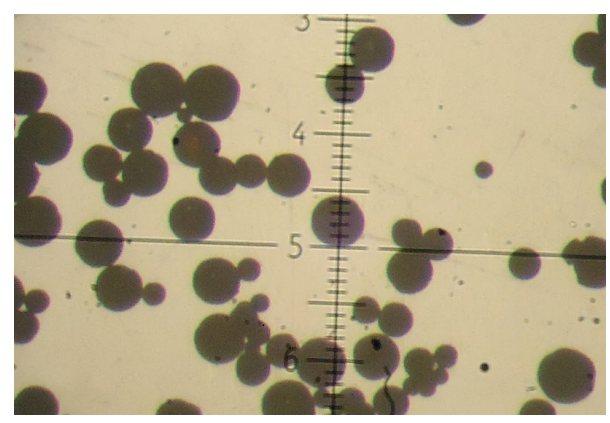

FIGURE 1: Optical microscopic picture of the resin. (One small division in the inserted scale is $30 \mu \mathrm{m}$.)

where $q_{e}$ is adsorption capacity at equilibrium in $(\mu \mathrm{mol} / \mathrm{g})$, $q_{t}$ is adsorption capacity at time " $t$ " in $(\mu \mathrm{mol} / \mathrm{g}), k_{1}\left(\mathrm{~min}^{-1}\right)$ is the rate constant of the pseudo-first order degradation rate of $\mathrm{Cr}(\mathrm{VI})$ to $\mathrm{Cr}(\mathrm{III})$, and pseudo-first-order rate can be calculated by plotting $\ln \left(q_{e}-q_{t}\right)$ versus time " $t$ ".

The linear form of pseudo-second-order equation is [25] as follows:

$$
\frac{t}{q_{t}}=\frac{1}{k_{2} q_{e}^{2}}+\frac{t}{q_{e}}
$$

where $k_{2}(\mu \mathrm{mol} / \mathrm{g} \cdot \mathrm{min})$ is the rate constant of the degradation rate of $\mathrm{Cr}(\mathrm{VI})$ by $\mathrm{n}$-ZVI and pseudo-second-order sorption of $\mathrm{Cr}(\mathrm{III})$ and $\mathrm{Fe}(\mathrm{III})$ ions to the porous support material. Slope of the plots $t / q_{t}$ versus $t$ was used to calculate the pseudosecond-order rate constant.

\section{Results and Discussion}

The copolymer beads obtained by the chain reaction of two monomers, that is, ethyl acrylate and 1,7-octadiene, are soft, gelatinous, hydrophobic and semitransparent, and not settled in separate state as the dry volumes are not possible. In the absence of solvent, the microstructure obtained of the resin is gel type even at $20 \%$ cross-linking. But after hydrolysis with $\mathrm{H}_{2} \mathrm{SO}_{4}$ and drying, the particles are in the form of free flowing. There were no signs of cracks or breakages in optical microscopic picture as shown in Figure 1.

This means that the particles are supposed to be physically stable because the resins are strong enough to stand osmotic shock where the medium was suddenly changed from acid to neutral. Long chain in this polymer imparts good flexibility as reported earlier in our study [7]. The general characteristics of the copolymer ethyl acrylate-co-1,7-octadiene and the acrylic acid resin derived from it are given in Table 1. Table 1 shows the better results of volume capacity, that is, $3.28 \mathrm{meq} / \mathrm{mL}$ (without diluents) as compared to our previous reported capacity which was $3.05 \mathrm{meq} / \mathrm{mL}$ (diluents $\mathrm{n}$-heptane, $20 \%$ ) [7]. The variation of capacity results may be due to the main structure of the polymer and deduced that the gel type of the resin may perform better.

FTIR Characterization. FTIR characterization of the copolymer and the resin derived from ethyl acrylate-co-1,7octadiene was reported and interpreted in detail in our early

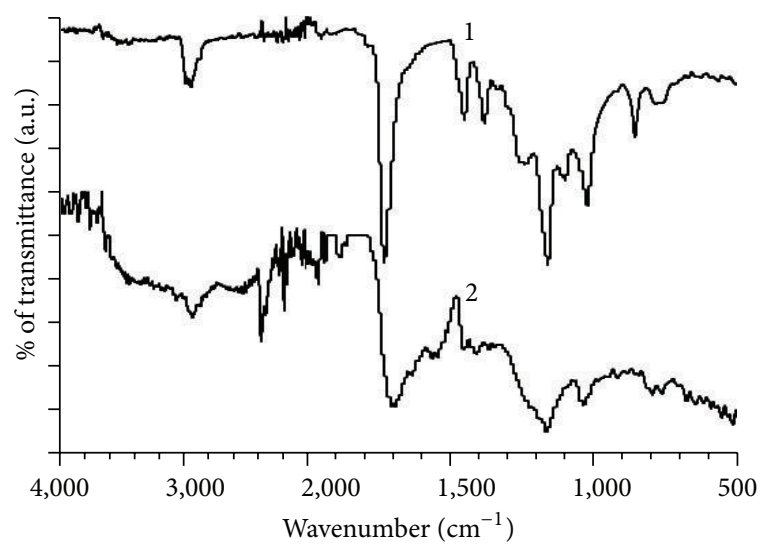

FIGURE 2: IR spectra of the (1) base copolymer and (2) acrylic acid resin derived after acid hydrolysis.

study [7]. In Figure 2 curve 1 related with the copolymer and shows that the signal at $2800-3000 \mathrm{~cm}^{-1}$ is due to $\mathrm{C}-\mathrm{H}$ bond of the monomer and cross-linking agent, that is, long chain of 1,7-octadiene which after copolymerization has been converted to saturated hydrocarbon.

Strong peak in spectra at $1700-1800 \mathrm{~cm}^{-1}$ with maximum at $1730 \mathrm{~cm}^{-1}$ is due to $\mathrm{C}=\mathrm{O}$ group, which is also seen in curve 2 but at $1700 \mathrm{~cm}^{-1}$. In Figure 2 curve 2 relates to the acrylic acid derived from the base copolymer of 1,7-octadiene and shows the signal at $2800-3000 \mathrm{~cm}^{-1}$ corresponding to $\mathrm{C}-\mathrm{H}$ bond. A strong peak at around $1700 \mathrm{~cm}^{-1}$ is due to the presence of $\mathrm{C}=\mathrm{O}$ group in the resin and the peak at $3000-3600 \mathrm{~cm}^{-1}$ is due to the moisture contents in the resin. The peak at around $117 \mathrm{~cm}^{-1}$ is due to the coupling between plane $\mathrm{OH}$ bending and $\mathrm{CO}$ stretching vibrations of neighboring carbonyl groups [26].

3.1. Characterization of INPs. Figure 3 shows the SEM image of the synthesized n-ZVI in two different magnifications and it is indicated in the figure that the iron nanoparticles are spherical and have chain-like conformation.

This chain-like morphology is because of magnetostatic attraction between the iron nanoparticles [27]. TEM image of the nanoparticles is shown in Figure 4 and shows that the particles size of the synthesized n-ZVI is in the range of 25$75 \mathrm{~nm}$ but some overlapped and small particles are also shown in the image.

Figure 5 is related to electrical properties and shows that the current and voltage drawn each parallel at room temperature in the range of -0.1 to $1.0 \mathrm{~V}$. The linear behaviour of the curve with respect to each other shows that with the increase of voltage the current also increases which reveals good conduction behaviour of the iron nanoparticles. So the synthesized iron nanoparticles in present study imparted good conduction and have sufficiently high metallic behaviour. A similar behaviour was also observed at millivoltage range and also shows the linear behaviour with respect to current.

XRD profile as shown in Figure 6 indicates the basic reflection peak at $2 \theta$ of $44.8^{\circ}$ which corresponds with the zero 
TABLE 1: Characteristics of ethyl-acrylate-co-1,7-octadiene and acrylic acid derived from it.

\begin{tabular}{lcccccccc}
\hline $\begin{array}{l}\text { X-linking } \\
(\%)\end{array}$ & Wt. $(\mathrm{g})$ & $V(\mathrm{~mL})$ & $\begin{array}{c}\text { Particle size } \\
(\mu \mathrm{m})\end{array}$ & $\begin{array}{c}\text { Mean diameter } \\
(\mu \mathrm{m})\end{array}$ & $\begin{array}{c}\text { Surface area } \\
\left(\mathrm{m}^{2} / \mathrm{kg}\right)\end{array}$ & $\begin{array}{c}\text { Dispersal } \\
\text { coefficient }\end{array}$ & $\begin{array}{c}d \\
(\mathrm{~g} / \mathrm{mL})\end{array}$ & $\begin{array}{c}\text { Capacity } \\
\mathrm{meq} / \mathrm{g} \mathrm{meq} / \mathrm{mL}\end{array}$ \\
\hline 20 & 6.73 & 13.26 & $45-150$ & 133 & 18.16 & 1.39 & 0.79 & 8.90 \\
\hline
\end{tabular}

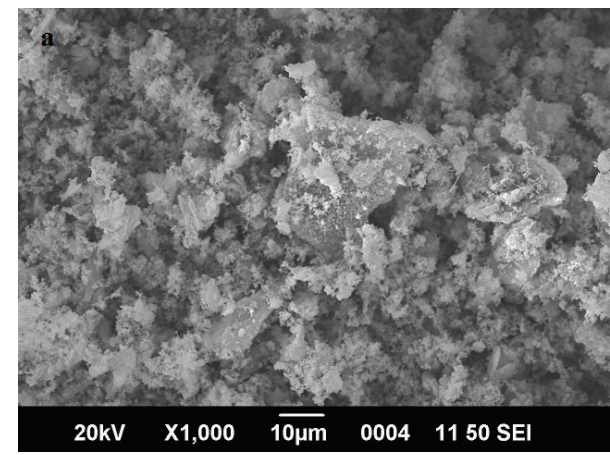

(a)

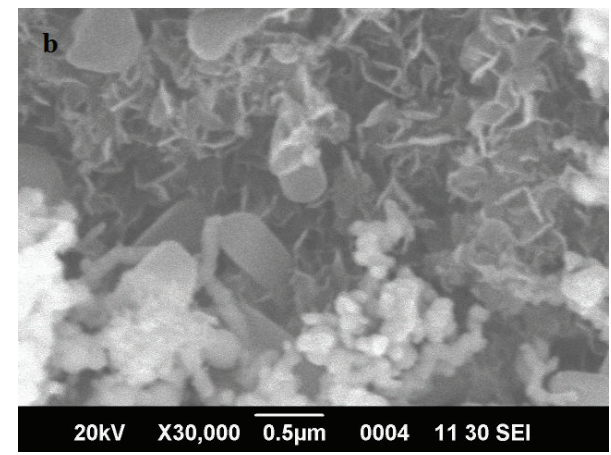

(b)

FIGURE 3: Scanning electron microscope image of synthesized iron nanoparticles (a) at $10 \mu \mathrm{m}$ and (b) at $0.5 \mu \mathrm{m}$.

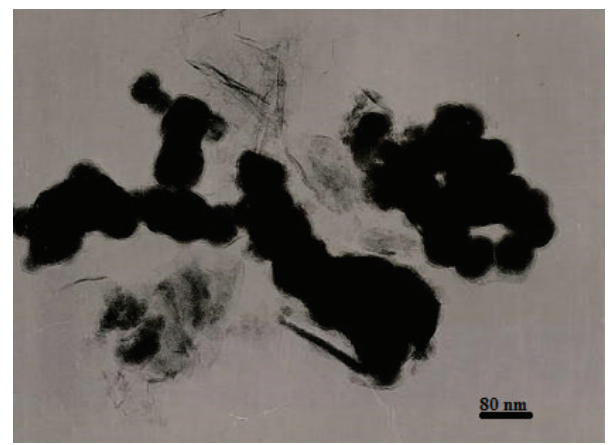

Figure 4: Transmission electron microscope image of the synthesized iron nanoparticles.

valent iron. The peak intensity at $2 \theta=44.8^{\circ}$ is very close to the previously reported work [27, 28]. All other peaks correspond to the iron oxides or other impurities. However, it is difficult to evaluate all the peaks except the peaks corresponding with the zero valent iron because the intensity of the peaks is very low and the XRD profile is poorly ordered and exhibits amorphous structure.

Such amorphous nature of zero valent iron has been reported in some previous literature with $\mathrm{FeCl}_{3}$ as a precursor and $\mathrm{KBH}_{4}$ as a reducing agent in the preparation of iron nanoparticles [10]. Low intensity profile of XRD obtained in this study and like the previous studies may be linked due to the smaller size of INPs [29] and the presence of the smaller sizes of the iron nanoparticles has been verified in TEM images as shown in Figure 3. Surface area (BET) of synthesized n-ZVI particles is obtained, the average $28.92 \mathrm{~m}^{2} / \mathrm{g}$, which is very close to the reported values in the literature $[22,30,31]$.

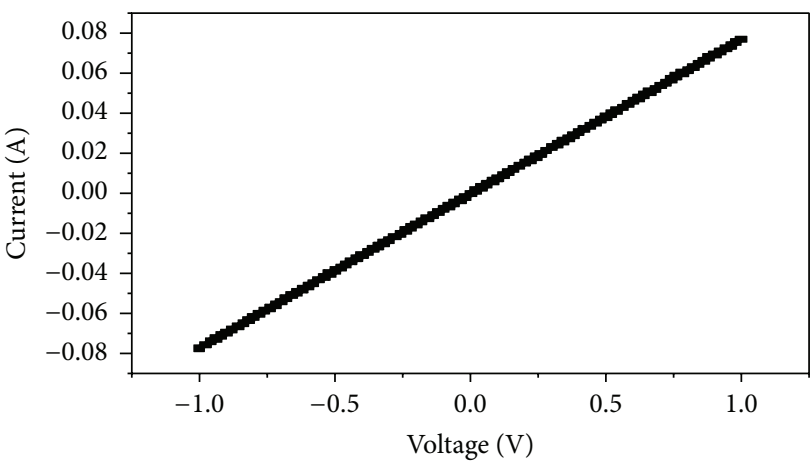

FIGURE 5: It shows the relationship of voltage and currents of the iron naoparticles.

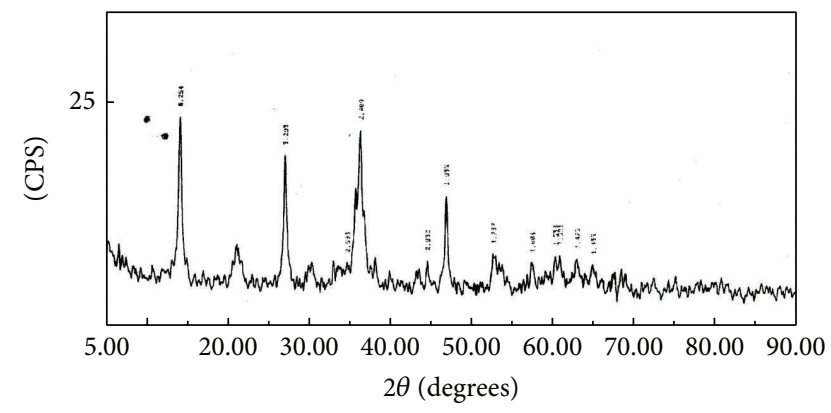

FIGURE 6: XRD pattern of synthesized iron nanoparticles.

3.2. Reduction of $\mathrm{Cr}$ (VI) and Enrichment of $\mathrm{Fe}$ (III) and $\mathrm{Cr}$ (III) onto the Polymer Surface. Cr(VI) reduces itself immediately and efficiently in contact with the potential applied by the zero valent iron in a very simply stoichiometric ratio [32] as given in (7). Figure 7 also illustrates the reduction capacity 
TABLE 2: Kinetics of reduction of Cr(VI) by varying amount of $n-Z V I$.

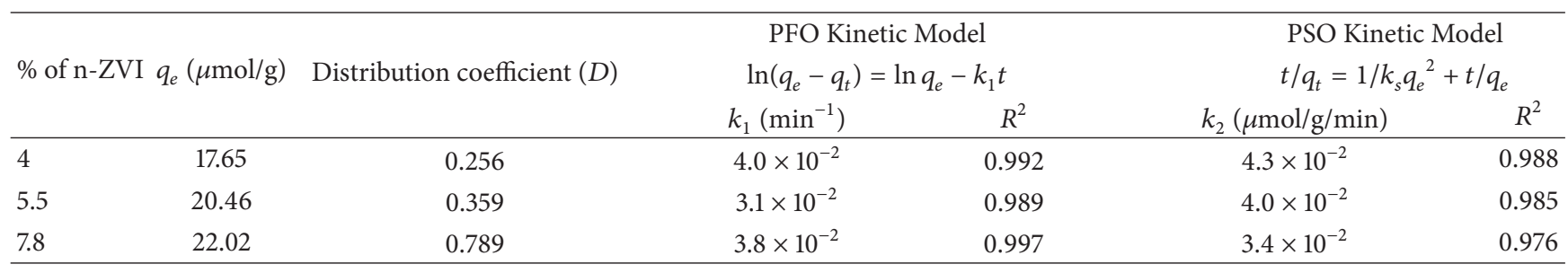

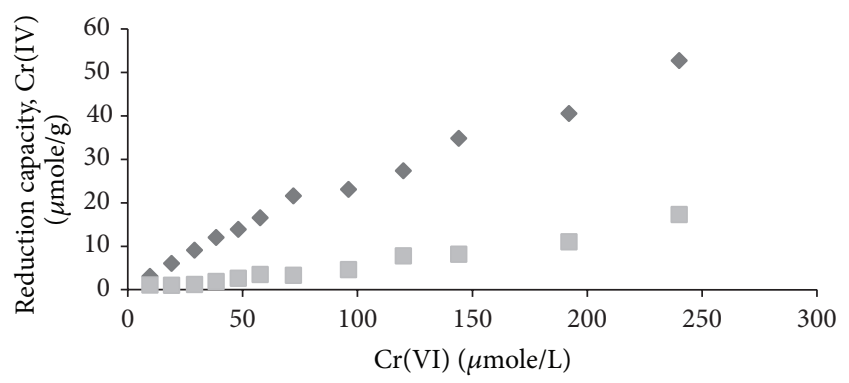

FIGURE 7: Reduction capacity of Cr(IV) with iron nanoparticles: loaded onto gel type weak acid resin of diameter ranging $45-150 \mu \mathrm{m}$, - = powder, without support.

of $\mathrm{Cr}(\mathrm{VI})$ as a function of initial $\mathrm{Cr}(\mathrm{VI})$ concentration up to $240 \mu \mathrm{mol} / \mathrm{L}$, and also given in the following equation:

$$
2 \mathrm{Fe}^{0}+\mathrm{Cr}_{2} \mathrm{O}_{7}^{2-}+14 \mathrm{H}^{+} \longrightarrow 2 \mathrm{Cr}^{3+}+2 \mathrm{Fe}^{3+}+7 \mathrm{H}_{2} \mathrm{O}
$$

The use of support material prevents agglomeration, which produces greater hydraulic surface conductivity and high specific surface area [9]. Thus the reduction capacities were obtained profoundly high as compared to the iron nanoparticles applied without support material for the reduction of $\mathrm{Cr}(\mathrm{VI})$ as in Figure 7 . When comparing these results with the previous study, where we use porous strong acid support, it can be seen that the reduction capacity of $\mathrm{Cr}(\mathrm{VI})$ with the iron nanoparticles is slightly less for the weak acid support as compared to porous strong acid support. Therefore, we can conclude that the porous support has some advantages, but the weak acid support possesses higher capacity as compared to the strong acid capacity which plays key role for the picking of trivalent cations.

As a result of reduction of $\mathrm{Cr}(\mathrm{VI})$ by iron nanoparticles the formation of two trivalent ion of chromium and iron was absorbed by the weak acid cationic supported as given in Figure 8 and illustrated in (6), (7), and (9). So it is proved from the results that the gel type functional polymer support not only disperses the INPs for the enhancement of reduction rates of $\mathrm{Cr}(\mathrm{VI})$ to $\mathrm{Cr}(\mathrm{III})$ but also enriches the cations from the aqueous media. Adsorption capacities of $\mathrm{Fe}$ (III) are higher than for the adsorption capacities for $\mathrm{Cr}$ (III).

It shows that selectivity of $\mathrm{Fe}$ (III) towards the gel type weak acid cation exchange resin is higher. This observation is in agreement with results reported in literature where

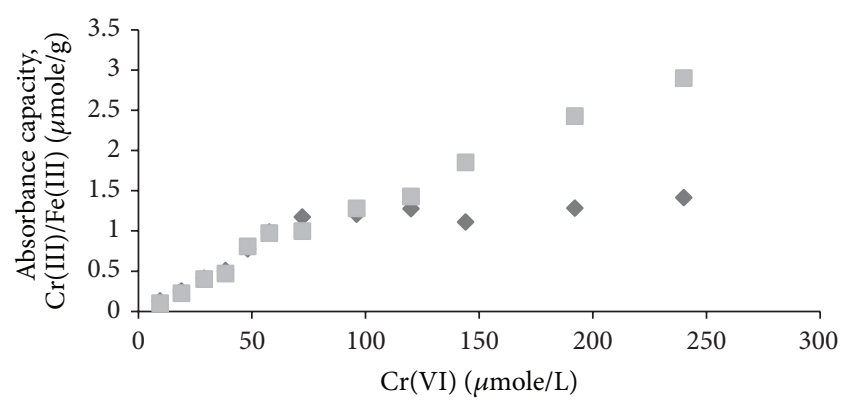

FIGURE 8: Absorption capacity of $\bullet=\mathrm{Cr}$ (III) and $\boldsymbol{\square}=\mathrm{Fe}$ (III) onto gel type weak acid support.

$\mathrm{Fe}(\mathrm{III})$ and $\mathrm{Cr}$ (III) ions were removed by using a chelating ion exchange resin "Diaion CR11" from aqueous media [33]:

$$
\begin{gathered}
3(\mathrm{P}-\mathrm{COOH})+\mathrm{Cr}^{3+}+3 \mathrm{H}_{2} \mathrm{O} \\
\longrightarrow(\mathrm{P}-\mathrm{COO})_{3} \mathrm{Cr}+3 \mathrm{H}_{3} \mathrm{O}^{+} \\
3(\mathrm{P}-\mathrm{COOH})+\mathrm{Fe}^{3+}+3 \mathrm{H}_{2} \mathrm{O} \\
\longrightarrow(\mathrm{P}-\mathrm{COO})_{3} \mathrm{Fe}+3 \mathrm{H}_{3} \mathrm{O}^{+}
\end{gathered}
$$

where $\mathrm{P}$ is polymer chain in the above equations. When comparing these results with the strong acid resin support with the same particle size, that is, $45-150 \mu$ [22], the results revealed that the absorption capacity for the trivalent cations is higher, that is, 2.9 and $1.414 \mu \mathrm{mol} / \mathrm{L}$ for $\mathrm{Fe}^{+3}$ and $\mathrm{Cr}^{+3}$, respectively, as compared to 1.85 and $0.901 \mu \mathrm{mol} / \mathrm{L}$ for the strong acid support at the dose level of $240 \mu \mathrm{mol} / \mathrm{L}$.

3.3. Kinetics Studies. The kinetic reduction of $\mathrm{Cr}(\mathrm{VI})$ to $\mathrm{Cr}$ (III) has been carried out with different amount of iron nanoparticles in the polymer support as shown in Figure 9. With increase of time the reduction capacity increases and settled at the maximum equilibrium position after about 120 minutes for all the dose levels (Table 2).

Table 3 showed that the equilibrium data having $4 \%$ of $n-$ ZVI having $R^{2}$ value 0.951 followed Freundlich adsorption isotherm model and explained the interaction of $\mathrm{Cr}(\mathrm{VI})$ and the adsorption of the newly generated ions towards the polymer support material. 
TABLE 3: Freundlich constant measurements. [ $T=298 \mathrm{~K}, \mathrm{Co}=96.1 \mu \mathrm{mole} / \mathrm{L}$, vol. $30 \mathrm{~mL}, \mathrm{pH}=5.2]$.

\begin{tabular}{lcrrr}
\hline \% of n-ZVI & $\begin{array}{c}\text { Linear relationship between } \ln q_{e} \text { and } \ln C_{e} \\
\ln q_{e}=\ln K_{F}+(1 / n) \ln C_{e}\end{array}$ & $R^{2}$ & $n$ & Freundlich constant " $K_{F}$ ” \\
\hline 4 & $y=0.180 x+4.776$ & 0.951 & 0.18 & 7.721 \\
5.5 & $y=0.289 x+4.909$ & 0.892 & 0.32 & 5.25 \\
7.8 & $y=0.780 x+5.899$ & 0.939 & 0.78 & 1.57 \\
\hline
\end{tabular}

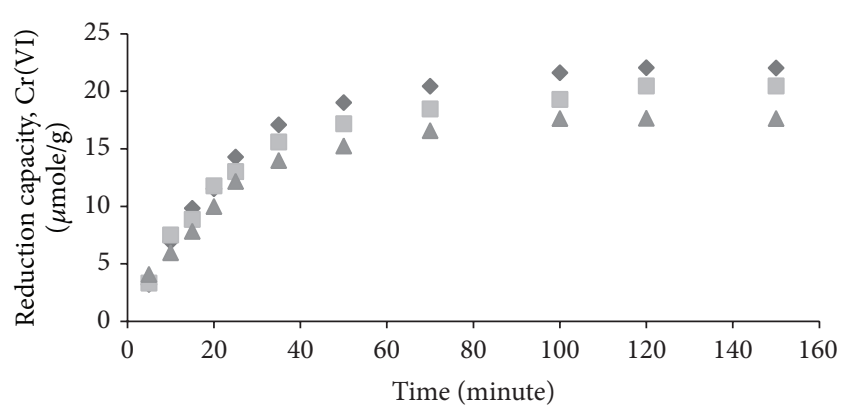

FIGURE 9: The kinetics curve of degradation of $\mathrm{Cr}(\mathrm{VI})$ by INPs $\diamond=$ $78 \mathrm{mg} / \mathrm{g}$ of support material; $\boldsymbol{\square}=55 \mathrm{mg} / \mathrm{g}$ of support material; $\boldsymbol{\Lambda}=$ $40 \mathrm{mg} / \mathrm{g}$ of the support material.

\section{Conclusions}

(1) The cross-linked acrylic acid resin based on ethylacrylate-1,7-octadiene can be synthesized in beads form by different amount of diluents and cross linking percentages to get distinct characteristics of resin for desirable applications.

(2) The synthesized acrylic acid resin is good enough to disperse iron nanoparticles onto its surface for the reduction of $\mathrm{Cr}(\mathrm{VI})$ to $\mathrm{Cr}(\mathrm{III})$ and subsequent enrichment of its byproducts, that is, Fe(III) and $\mathrm{Cr}$ (III), by the same resin in a single step is a new era in the world of weak acid resin.

(3) So in our present study, the use of weak acid cationic support material is helpful for capturing of produced ions, that is, $\mathrm{Fe}(\mathrm{III})$ and $\mathrm{Cr}(\mathrm{III})$ from the reaction mixture.

(4) Results showed that the equilibrium data having 4\% of n-ZVI having $R^{2}$ value 0.951 followed Freundlich isotherm model.

\section{Conflict of Interests}

The authors declare that there is no conflict of interests regarding the publication of this paper.

\section{Acknowledgments}

The authors thank Dr. Jamshed Hussain Zaidi (PINSTECH) for XRD analysis, Mr. Javed Iqbal (NIBGE) for TEM analysis, Dr. Tariq Yasin for IR and BET surface area analysis, and Dr. Tanvir Ahmad for composing and drawing the figure in this paper. This work is a part of Ph.D thesis of Syed Wasim Ali.

\section{References}

[1] K. Dofner, Ion Exchangers, Walter de Gruyter, New York, NY, USA, 1991.

[2] A. Dąbrowski, Z. Hubicki, P. Podkościelny, and E. Robens, "Selective removal of the heavy metal ions from waters and industrial wastewaters by ion-exchange method," Chemosphere, vol. 56, no. 2, pp. 91-106, 2004.

[3] C. E. Harland, Ion Exchange: Theory and Practice, Royal Society of Chemistry, London, UK, 1994.

[4] F. C. Nachod and J. Schubert, Ion Exchange Technology, Academic Press, New York, NY, USA, 1956.

[5] R. Kunin and R. E. Barry, "Carboxylic, weak acid type, cation exchange resin," Industrial \& Engineering Chemistry, vol. 41, no. 6, pp. 1269-1272, 1949.

[6] P. Meyers, "Applications of weak acid cation resin in waste treatment," in Proceedings of the Annual International Technical Conference (AESF SUR/FIN '99), pp. 609-618, American Electroplaters and Surface Finishers Society, Cincinnati, Ohio, USA, June 1999.

[7] S. Wasim Ali, M. A. Malik, S. Jan, and K. Naeem, "Comparison of rigid divinylbenzene with flexible 1,7-octadiene crosslinks in acrylic acid resins-effects on kinetics of swelling and loading of heavy metal ions from water," Journal of Applied Polymer Science, vol. 131, no. 21, Article ID 41038, 2014.

[8] F. Fu, J. Ma, L. Xie, B. Tang, W. Han, and S. Lin, "Chromium removal using resin supported nanoscale zero-valent iron," Journal of Environmental Management, vol. 128, pp. 822-827, 2013.

[9] S. M. Ponder, J. G. Darab, J. Bucher et al., "Surface chemistry and electrochemistry of supported zerovalent iron nanoparticles in the remediation of aqueous metal contaminants," Chemistry of Materials, vol. 13, no. 2, pp. 479-486, 2001.

[10] Y. Li, Z. Jin, T. Li, and S. Li, "Removal of hexavalent chromium in soil and groundwater by supported nano zero-valent iron on silica fume," Water Science and Technology, vol. 63, no. 12, pp. 2781-2787, 2011.

[11] C. J. Lin, S.-L. Lo, and Y. H. Liou, "Degradation of aqueous carbon tetrachloride by nanoscale zerovalent copper on a cation resin," Chemosphere, vol. 59, no. 9, pp. 1299-1307, 2005.

[12] H. Gu, S. B. Rapole, J. Sharma et al., "Magnetic polyaniline nanocomposites toward toxic hexavalent chromium removal," RSC Advances, vol. 2, no. 29, pp. 11007-11018, 2012.

[13] B. Qiu, H. Gu, X. Yan et al., "Cellulose derived magnetic mesoporous carbon nanocomposites with enhanced hexavalent chromium removal," Journal of Materials Chemistry A, vol. 2, no. 41, pp. 17454-17462, 2014.

[14] F. Gao, H. Gu, H. Wang, X. Wang, B. Xiang, and Z. Guo, "Magnetic amine-functionalized polyacrylic acid-nanomagnetite for hexavalent chromium removal from polluted water," RSC Advances, vol. 5, no. 74, pp. 60208-60219, 2015. 
[15] E. Pehlivan and S. Cetin, "Sorption of $\mathrm{Cr}(\mathrm{VI})$ ions on two Lewatit-anion exchange resins and their quantitative determination using UV-visible spectrophotometer," Journal of Hazardous Materials, vol. 163, no. 1, pp. 448-453, 2009.

[16] H. Tahir, M. Saleem, M. Afzal, H. Ahmad, S. T. Hussain, and J. Afzal, "Estimation and removal of chromium ions from tannery wastes using zeolite-3A," Adsorption Science \& Technology, vol. 16, no. 3, pp. 153-161, 1998.

[17] H. Tahir, "Comparative trace metal contents in sediments and liquid wastes from tanneries and the removal of chromium using Zeolite-5A," Electronic Journal of Environmental, Agricultural and Food Chemistry, vol. 4, no. 4, pp. 1021-1032, 2005.

[18] C. Balan, D. Bilba, and M. Macoveanu, "Studies on chromium(III) removal from aqueous solutions by sorption on Sphagnum moss peat," Journal of the Serbian Chemical Society, vol. 74, no. 8-9, pp. 953-964, 2009.

[19] S. Heydari, H. Sharififard, M. Nabavinia, H. Kiani, and M. Parvizi, "Adsorption of chromium ions from aqueous solution by carbon adsorbent," International Journal of Environmental, Chemical, Ecological, Geological and Geophysical Engineering, vol. 7, no. 12, pp. 649-652, 2013.

[20] B. K. Baruah, B. Das, A. Haque, K. Misra, and A. K. Misra, "Iron removal efficiency of different bamboo charcoals: a study on modified indigenous water filtration technique in rural areas of Assam," Journal of Chemical and Pharmaceutical Research, vol. 3, no. 2, pp. 454-459, 2011.

[21] W. Agnieszka, C. Lucjan, Z. Pawal et al., "Adsorbents for iron removal obtained from vermiculite," Acta Geodynamica et Geomaterialia, vol. 10, no. 3, pp. 353-361, 2013.

[22] S. W. Ali, M. L. Mirza, and T. M. Bhatti, "Removal of Cr(VI) using iron nanoparticles supported on porous cation-exchange resin," Hydrometallurgy, vol. 157, pp. 82-89, 2015.

[23] L. Wu, M. Shamsuzzoha, and S. M. C. Ritchie, "Preparation of cellulose acetate supported zero-valent iron nanoparticles for the dechlorination of trichloroethylene in water," Journal of Nanoparticle Research, vol. 7, no. 4-5, pp. 469-476, 2005.

[24] M. I. Din, M. L. Mirza, S. Ata, M. Athar, and I. U. Mohsin, "Thermodynamics of biosorption for removal of Co(II) ions by an efficient and ecofriendly biosorbent (Saccharum bengalense): kinetics and isotherm modeling," Journal of Chemistry, vol. 2013, Article ID 528542, 11 pages, 2013.

[25] Y.-S. Ho, "Review of second-order models for adsorption systems," Journal of Hazardous Materials, vol. 136, no. 3, pp. 681689, 2006.

[26] M. A. Moharram, S. M. Rabie, and H. M. El-Gendy, "Infrared spectra of $\gamma$-irradiated poly(acrylic acid)-polyacrylamide complex," Journal of Applied Polymer Science, vol. 85, no. 8, pp. 16191623, 2002.

[27] Y. Xi, M. Megharaj, and R. Naidu, "Dispersion of zerovalent iron nanoparticles onto bentonites and use of these catalysts for orange II decolourisation," Applied Clay Science, vol. 53, no. 4, pp. 716-722, 2011.

[28] C. J. Choi, O. Tolochko, and B. K. Kim, "Preparation of iron nanoparticles by chemical vapor condensation," Materials Letters, vol. 56, no. 3, pp. 289-294, 2002.

[29] Y.-H. Lin, H.-H. Tseng, M.-Y. Wey, and M.-D. Lin, "Characteristics of two types of stabilized nano zero-valent iron and transport in porous media," Science of the Total Environment, vol. 408 , no. 10 , pp. $2260-2267,2010$.
[30] T.-T. Lim, J. Feng, and B.-W. Zhu, "Kinetic and mechanistic examinations of reductive transformation pathways of brominated methanes with nano-scale Fe and Ni/Fe particles," Water Research, vol. 41, no. 4, pp. 875-883, 2007.

[31] R. J. Barnes, C. J. van der Gast, O. Riba et al., "The impact of zero-valent iron nanoparticles on a river water bacterial community," Journal of Hazardous Materials, vol. 184, no. 1-3, pp. 73-80, 2010.

[32] P. V. V. V. Prasad, C. Das, and A. K. Golder, "Reduction of Cr(VI) to $\mathrm{Cr}$ (III) and removal of total chromium from wastewater using scrap iron in the form of zerovalent iron(ZVI): batch and column studies," Canadian Journal of Chemical Engineering, vol. 89, no. 6, pp. 1575-1582, 2011.

[33] S. Fernandes, I. S. Romão, C. M. R. Abreu, M. J. Quina, and L. M. Gando-Ferreira, "Selective separation of $\mathrm{Cr}$ (III) and Fe(III) from liquid effluents using a chelating resin," Water Science and Technology, vol. 66, no. 9, pp. 1968-1976, 2012. 

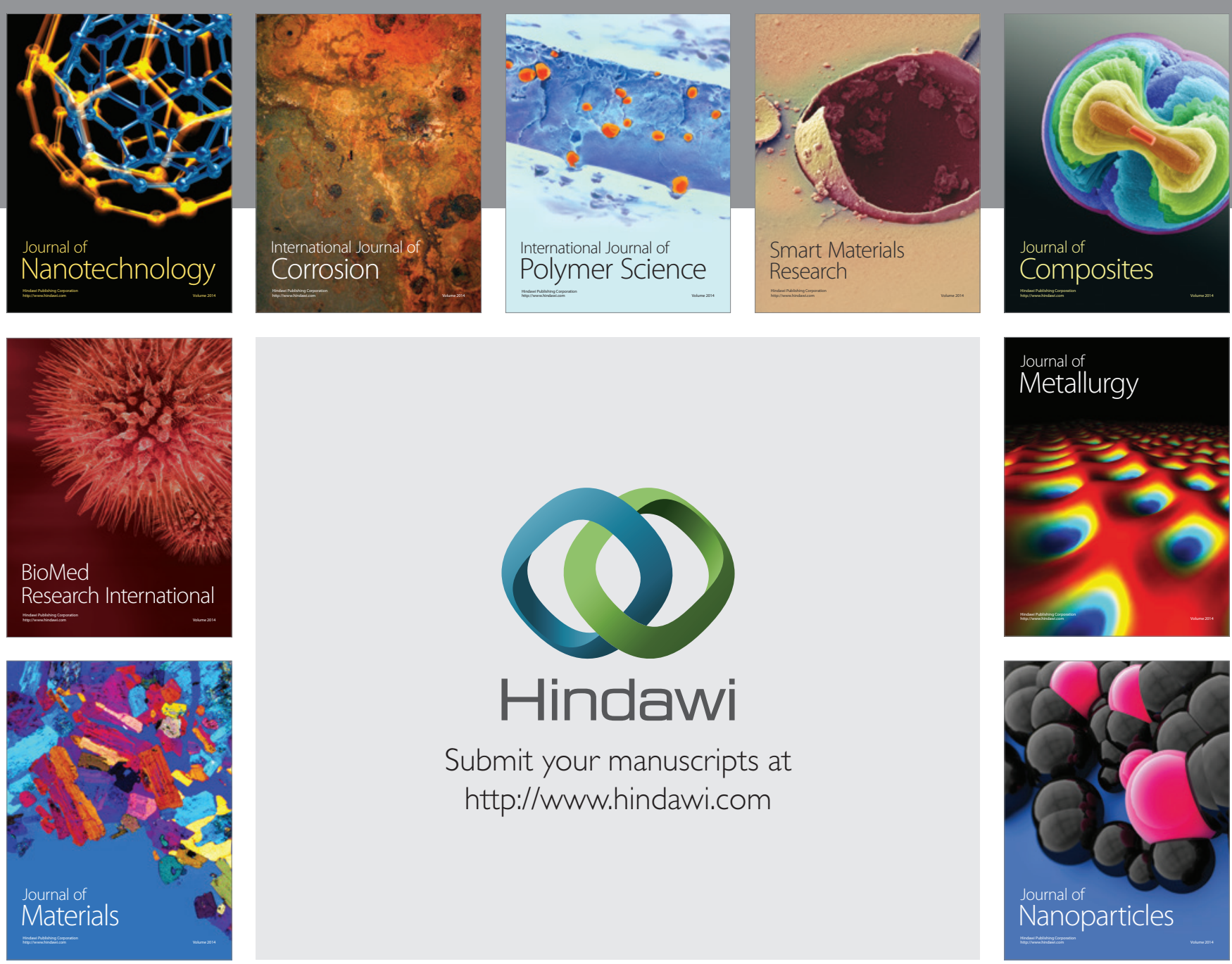

Submit your manuscripts at http://www.hindawi.com
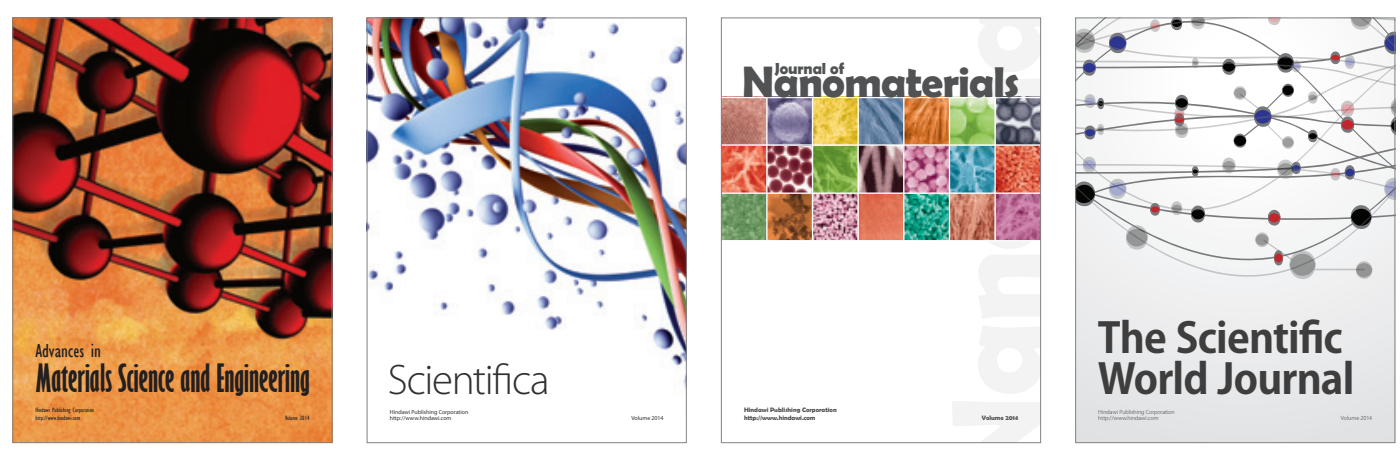

\section{The Scientific World Journal}
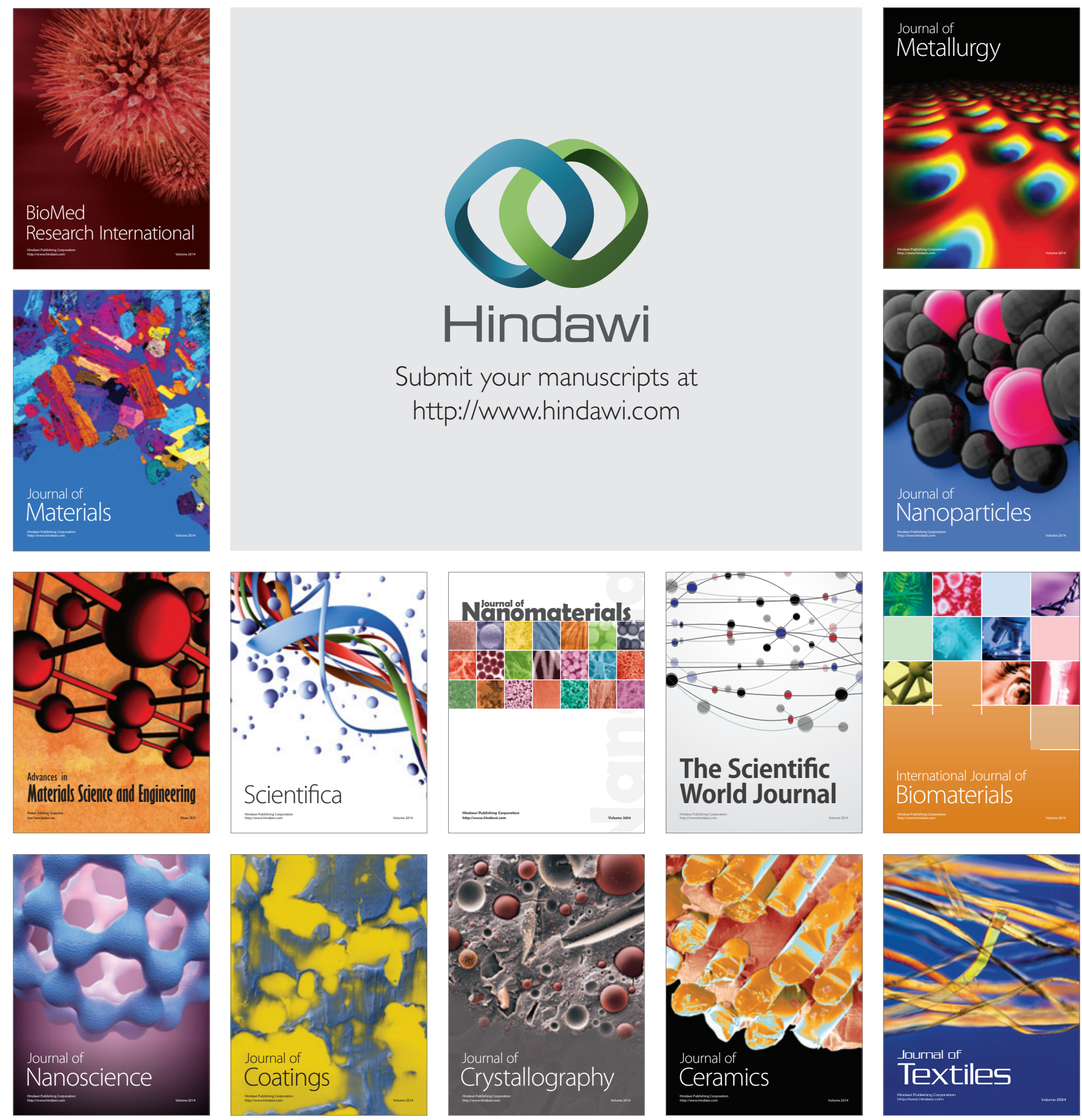